\title{
Maximum rainfall probability distributions pattern in Haryana -A case study
}

\author{
Manoj Kumar ${ }^{1 *}$, Chander Shekhar ${ }^{2}$ and Veena Manocha ${ }^{3}$ \\ ${ }^{1}$ College of Agriculture, CCS Haryana Agricultural University, Kaul (Kaithal)- 136021 (Haryana), INDIA \\ ${ }^{2}$ Rice Research Station, CCS Haryana Agricultural University, Kaul (Kaithal)- 136021 (Haryana), INDIA \\ ${ }^{3}$ Directorate Human Resource Management, CCS Haryana Agricultural University, Hisar- 125004 (Haryana), INDIA \\ *Corresponding author. E-mail: m25424553@gmail.com
}

Received: January 13, 2016; Revised received: July 20, 2016; Accepted: November 5, 2016

\begin{abstract}
The present study has been undertaken to fit best probability distribution of rainfall in Ambala District of Haryana State. The analysis showed that the maximum daily rainfall among the years ranged between $41 \mathrm{~mm}(1980)$ to $307.9 \mathrm{~mm}$ (2009) indicating a very large variation during the period of study. The mean of maximum daily rainfall of all years annually is $112.13 \mathrm{~mm}$. The means of monthly and weekly values ranged from $33.10-88.92 \mathrm{~mm}$ and 8.77 $46.28 \mathrm{~mm}$, respectively. The maximum daily rainfall in a year/monsoon season was $307.9 \mathrm{~mm}$ and monthly maximum daily rainfall in monsoon season ranged from $105-307.9 \mathrm{~mm}$. The weekly maximum daily rainfall ranged from48 mm-307.9 mm. It was also observed that the minimum among the maximum daily rainfall was $41 \mathrm{~mm}$ for annual, $34 \mathrm{~mm}$ for season and 0 in all the months and weeks. The maximum value of coefficient of variation was observed in the first week which indicated a large fluctuation in the rainfall data set and minimum value of coefficient of variation 0.464 was observed for the whole year which shows that fluctuation was minimum for the whole year. Generalized extreme value distribution was found to be best fit probability distribution for most of the periods.
\end{abstract}

Keywords: Goodness-of-fit tests, Maximum rainfall, Probability distributions

\section{INTRODUCTION}

It has long been a topic of interest in the fields of climatology to find a probability distribution that provides a good fit to daily rainfall. Several studies have been conducted in India and abroad on rainfall analysis and best fit probability distribution function such as normal, log-normal, gumbel, weibull and Pearson type distribution were identified (Mayooran, and laheetharan, 2014).

Rama Rao et al. (1975) analyzed the daily rainfall data collected at Bijapur for the year 1921 to 1970 at Bihapur. K N Krishnamurthy et al. (2015) studied the distribution of rainfall in the Bengaluru Urban District and observed that normal distribution was found to be the best for annual and seasonal months whereas gamma (2P), Weibull (3P) and general extreme distributions were found to be the best fit probability distributions for most of the weekly periods. Duan et al. (1995) suggested that for modeling daily rainfall data, the weibull and to a lesser extent the exponential distribution is suitable. Upadhaya and Singh (1998) stated that it is possible to predict rainfall more accurately using various probability distributions for certain returns period although the rainfall varies with space, time and have erratic nature. Sen and Eljadid (1999) reported that for monthly rainfall in arid regions, Gamma probability distribution is the best fit.

Ogunlela (2001) observed that log-Pearson type III distribution is best to describe the stochastic analysis of peak daily rainfall. Tao et al. (2002) recommended generalized extreme value model as the most suitable distribution after a systematic assessment procedure for representing extreme-value process and its relatively simple parameter estimation. Salami (2004) studied the meteorological data for Texas and found that Gumbel distribution fits adequately for both evaporation and temperature data, while for precipitation data logPearson type III distribution confirms to be more accurate. Takara et al. (2013) analyzed the extreme events and revealed that hydrological extremes sometimes do not fit well to the theoretical extreme-value distribution such as the Bumbel and generalized extreme value distributions. Lee (2005) indicated that log-Pearson type III distribution fits for $50 \%$ of total station number for the rainfall distribution characteristics of ChiaNan plain area.

Bhakar et al. (2006) observed the frequency analysis of consecutive days peaked rainfall at Banswara, Rajasthan, India, and found gamma distribution as the best fit distribution. Kwaku et al. (2007) revealed that the log-normal distribution was the best fit probability distribution for one to five consecutive days' maximum rainfall for Accra, Ghana. Hanson et al. (2008) indicated that Pearson type III distribution fits the full record of daily precipitation data and Kappa distribution describes best the observed distribution of wet-day daily rainfall. Olofintoye et al. (2009) examined that 
$50 \%$ of the total station number in Nigeria follows logPearson type III distribution for peak daily rainfall, while $40 \%$ and $10 \%$ of the total station follows Pearson type III and log-Gumbel distribution, respectively. It is the distribution of rainfall during a season rather than its total amount which influence the crop yield. Water management of a country also depends on the pattern and distribution of rainfall.In view of this, the present study has been planned to establish the methodology for identifying the best fit probability distribution on the basis of three types goodness of fit tests. The maximum rainfall data of a single site (Ambala District, Haryana) was used to select a best fit probability distribution for rainfall.

\section{MATERIALS AND METHODS}

The present study is based on time series data of maximum daily rainfall in a year, season, month and week. The maximum daily, weekly, monthly, seasonal and annual rainfall data of 47 years (1966 to 2013) were collected from the India Meteorological Department. Various probability distributions namely normal, lognormal (2P, 3P), gamma (2P, 3P), generalized gamma $(3 \mathrm{P}, 4 \mathrm{P})$, log-gamma, weibull $(2 \mathrm{P}, 3 \mathrm{P})$, Pearson 5 (2P, 3P), Pearson 6 (3P, 4P), log-Pearson 3, generalized extreme value were fitted and evaluated by using the Komogorov-Smirnov, Anderson Darling and Chisquare tests. Different steps/ methods were used to find out the results

Step I: Fitting the probability distribution: The probability distributions viz. normal, lognormal, gamma, weibull, Pearson, generalized extreme value were identified to evaluate the best fit probability distribution for rainfall pattern. In addition to these different forms of distributions some other distribution were also tried and thus total 16 probability distributions viz. normal, lognormal (2P, 3P), gamma (2P, 3P), generalized gamma (3P, 4P), log-gamma, weibull (2P, $3 \mathrm{P})$, Pearson 5 (2P, 3P), Pearson 6 (3P, 4P), logPearson 3, generalized extreme value were applied to find out the best fit probability distribution. The description of various probability distribution functions viz. density function, range and the parameters involved are presented in Table 1.

Step II: Testing the goodness of fit: The goodness of fit test measures the compatibility of random sample with the theoretical probability distribution. The goodness of fit tests was applied for testing the following null hypothesis:

$\mathrm{H}_{0}$ : The maximum daily rainfall data follow the specified distribution

$\mathrm{H}_{\mathrm{A}}$ : The maximum daily rainfall data does not follow the specified distribution.

The following goodness of fit tests viz. KolmogorovSmirnov test and Anderson-Darling test were used along with the chi-square test at $\alpha(0.01)$ level of significance for the selection of the best fit Probability distri- bution.

(i) Kolmogorov-smirnov Test: The KolmogorovSmirnov statistic (D) is defined as the largest vertical difference between the theoretical and the empirical cumulative distribution function (ECDF):

$\mathrm{D}=\max \left[F\left(x_{i}\right)-\frac{i-1}{n} \cdot \frac{i}{n}-F\left(x_{i}\right)\right]$

Where $x_{i}=$ random sample, $i=1,2 \ldots n$.

$\mathrm{CDF}=\mathrm{F}_{\mathrm{n}}(\mathrm{x})=\frac{\mathbf{1}}{\mathrm{n}}[$ Number of observations $\leq \mathrm{x}](2)$

This test is used to decide if a sample comes from a hypothesized continuous distribution.

(ii) Anderson-darling test: The Anderson-Darling statistic $\left(\mathrm{A}^{2}\right)$ is defined as

$\mathrm{A}^{2}=-\mathrm{n}-\frac{1}{n} \sum_{i=1}^{n}(2 i-1) \cdot\left[\ln F\left(x_{i}\right)+\ln F\left(x_{n-i+1}\right)\right]$

It is a test to compare the fit of an observed cumulative distribution function to an expected cumulative distribution function. This test gives more weight to the tails then the Kolmogorov-Smirnov test.

(iii) Chi-squared test: $\chi 2$ The Chi-Squared statistic is defined as

$$
\chi 2=\sum_{i=1}^{\infty E} \frac{\left(O_{\bar{i}}-E_{i \bar{i}}\right)=}{E_{i \bar{i}}}
$$

Where

$\mathrm{O}_{\mathrm{i}}=$ observed frequency $\mathrm{E}_{\mathrm{i}}=$ expected frequency

' $\mathrm{i}$ ' $=$ number of observations $(1,2, \ldots \ldots . \mathrm{k})$

This test is for continuous sample data only and is used to determine if a sample comes from a population with a specific distribution.

Step III: Identification of best fit probability distribution: The three goodness of fit tests mentioned above were computed to the maximum rainfall data treating different data set. The test statistic of each test were computed and tested at $(\alpha=0.01)$ level of significance. Accordingly, the ranking of different probability distributions were marked from 1 to 16 based on minimum test statistic value. The distribution holding the first rank was selected for all the three tests independently. The assessments of all the probability distribution were made on the basis of total test score obtained by combining the entire three tests. Maximum score 16 was awarded to rank first probability distribution based on the test statistic and further less scores were awarded to the distribution having rank more than 1 , i.e. 2 to 16 . Thus the total score of the entire three tests were summarized to identify the best fit distribution on the bases of highest score obtained.

The probability distribution having the maximum score was included as a fourth probability distribution in addition to three probability distributions which were previously identified.

\section{RESULTS AND DISCUSSION}

The methodology presented above was applied to the 47 years weather data in which maximum rainfall 
Manoj Kumar et al. / J. Appl. \& Nat. Sci. 8 (4): 2029-2036 (2016)

Table 1. Description of various probability distribution functions((Mayooran, and laheetharan, 2014).




Manoj Kumar et al. / J. Appl. \& Nat. Sci. 8 (4): 2029-2036 (2016)

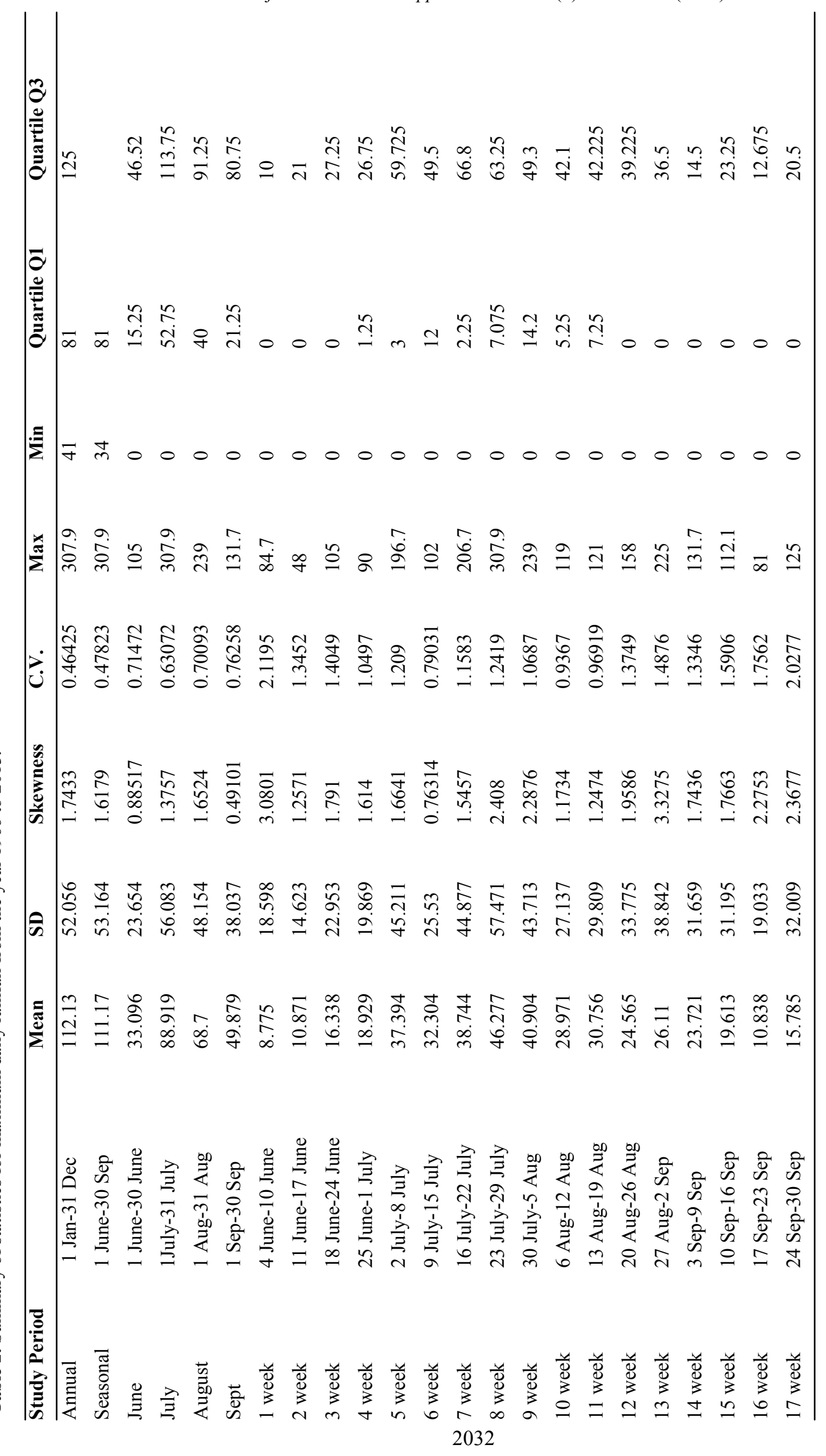


Manoj Kumar et al. / J. Appl. \& Nat. Sci. 8 (4): 2029-2036 (2016)

Table 3. Study period wise first ranked probability distribution using goodness of fit tests.

\begin{tabular}{|c|c|c|c|c|c|c|c|}
\hline & & \multicolumn{2}{|c|}{ Kolmogorov Smirnov } & \multicolumn{2}{|c|}{ Anderson Darling } & \multicolumn{2}{|c|}{ Chi-Square } \\
\hline Study Period & & Distribution & Statistics & $\begin{array}{l}\text { Distribu- } \\
\text { tion }\end{array}$ & $\begin{array}{l}\text { Statis- } \\
\text { tics }\end{array}$ & $\begin{array}{l}\text { Distribu- } \\
\text { tion }\end{array}$ & Statistics \\
\hline Annual & 1 Jan-31 Dec & Gen. Extreme & .07378 & $\begin{array}{l}\text { Gen. Ex- } \\
\text { treme }\end{array}$ & .02035 & $\begin{array}{l}\text { Lognormal } \\
\text { (3P) }\end{array}$ & 0.312888 \\
\hline Seasonal & 1 June-30 Sep & Gen. Extreme & .08439 & $\begin{array}{l}\text { Gen. Ex- } \\
\text { treme }\end{array}$ & .32114 & Pearson 6 & .85293 \\
\hline June & $\begin{array}{l}1 \text { June-30 } \\
\text { June }\end{array}$ & Gen. Extreme & .07294 & $\begin{array}{l}\text { Gen. Ex- } \\
\text { treme }\end{array}$ & .19153 & Gamma & 0.82822 \\
\hline July & 1July-31 July & Gen. Gamma & .08462 & $\begin{array}{l}\text { Gen. Ex- } \\
\text { treme }\end{array}$ & .39106 & $\begin{array}{l}\text { Gen. Ex- } \\
\text { treme }\end{array}$ & 0.79631 \\
\hline August & 1 Aug-31 Aug & Gen. Extreme & .09279 & $\begin{array}{l}\text { Gen. Ex- } \\
\text { treme }\end{array}$ & .6191 & Pearson 6 & 4.7585 \\
\hline Sept & $1 \mathrm{Sep}-30 \mathrm{Sep}$ & Gen. Extreme & .11961 & $\begin{array}{l}\text { Gen. Ex- } \\
\text { treme }\end{array}$ & .78035 & $\begin{array}{l}\text { Lognormal } \\
\text { (2P) }\end{array}$ & 0.93463 \\
\hline 1 week & $\begin{array}{l}4 \text { June-10 } \\
\text { June }\end{array}$ & Normal & .31853 & Weibull & -5.5831 & Normal & 14.073 \\
\hline 2 week & $\begin{array}{l}11 \text { June-17 } \\
\text { June }\end{array}$ & Normal & .24847 & Weibull & -1.6365 & Normal & 8.7168 \\
\hline 3 week & $\begin{array}{l}18 \text { June-24 } \\
\text { June }\end{array}$ & Normal & .2383 & Gamma & 1.7723 & Normal & 8.8549 \\
\hline 4 week & $\begin{array}{l}25 \text { June-1 } \\
\text { July }\end{array}$ & Gen. Extreme & .12316 & $\begin{array}{l}\text { Gen. Ex- } \\
\text { treme }\end{array}$ & 0.9657 & $\begin{array}{l}\text { Gen. Ex- } \\
\text { treme }\end{array}$ & 2.1798 \\
\hline 5 week & 2 July-8 July & Gen. Extreme & .12583 & $\begin{array}{l}\text { Gen. Ex- } \\
\text { treme }\end{array}$ & 0.9947 & $\begin{array}{l}\text { Gen. Ex- } \\
\text { treme }\end{array}$ & 1.0918 \\
\hline 6 week & 9 July-15 July & Gen. Extreme & .0828 & $\begin{array}{l}\text { Gen. Ex- } \\
\text { treme }\end{array}$ & 0.4454 & Normal & 1.6877 \\
\hline 7 week & $\begin{array}{l}16 \text { July-22 } \\
\text { July }\end{array}$ & Gen. Extreme & .13271 & $\begin{array}{l}\text { Gen. Ex- } \\
\text { treme }\end{array}$ & 1.3722 & Pearson 5 & 5.0899 \\
\hline 8 week & $\begin{array}{l}23 \text { July-29 } \\
\text { July }\end{array}$ & Gen. Extreme & .10819 & $\begin{array}{l}\text { Gen. Ex- } \\
\text { treme }\end{array}$ & 0.6685 & Pearson 5 & 1.9855 \\
\hline 9 week & 30 July-5 Aug & Gen. Extreme & .08376 & $\begin{array}{l}\text { Gen. Ex- } \\
\text { treme }\end{array}$ & 0.4512 & $\begin{array}{l}\text { Gamma } \\
(3 \mathrm{P})\end{array}$ & 1.3943 \\
\hline 10 week & 6 Aug-12 Aug & Gen. Extreme & .09081 & $\begin{array}{l}\text { Gen. Ex- } \\
\text { treme }\end{array}$ & .56004 & $\begin{array}{l}\text { Gen. Ex- } \\
\text { treme }\end{array}$ & 2.4656 \\
\hline 11 week & $\begin{array}{l}13 \text { Aug-19 } \\
\text { Aug }\end{array}$ & Gen. Extreme & .08791 & $\begin{array}{l}\text { Gen. Ex- } \\
\text { treme }\end{array}$ & .40648 & Gamma(3P) & 1.3868 \\
\hline 12 week & $\begin{array}{l}20 \text { Aug-26 } \\
\text { Aug }\end{array}$ & Gen. Extreme & .1665 & $\begin{array}{l}\text { Gen. Ex- } \\
\text { treme }\end{array}$ & 2.2935 & $\begin{array}{l}\text { Gen. Ex- } \\
\text { treme }\end{array}$ & 8.9913 \\
\hline 13 week & 27 Aug-2 Sep & Gen. Extreme & .13938 & $\begin{array}{l}\text { Gen. Ex- } \\
\text { treme }\end{array}$ & 1.1948 & $\begin{array}{l}\text { Gen. Ex- } \\
\text { treme }\end{array}$ & 3.1964 \\
\hline 14 week & 3 Sep-9 Sep & Gen. Extreme & .1765 & $\begin{array}{l}\text { Gen. Ex- } \\
\text { treme }\end{array}$ & 1.8772 & $\begin{array}{l}\text { Gen. Ex- } \\
\text { treme }\end{array}$ & 5.7725 \\
\hline 15 week & $\begin{array}{l}10 \text { Sep-16 } \\
\text { Sep }\end{array}$ & Gen. Extreme & .21102 & $\begin{array}{l}\text { Gen. Ex- } \\
\text { treme }\end{array}$ & 3.1495 & $\begin{array}{l}\text { Gen. Ex- } \\
\text { treme }\end{array}$ & 8.8568 \\
\hline 16 week & $\begin{array}{l}17 \text { Sep-23 } \\
\text { Sep }\end{array}$ & Normal & .28454 & $\begin{array}{l}\text { Weibull } \\
(3 \mathrm{P})\end{array}$ & -8.7009 & $\begin{array}{l}\text { Gen. Ex- } \\
\text { treme }\end{array}$ & 8.8169 \\
\hline 17 week & $\begin{array}{l}24 \text { Sep-30 } \\
\text { Sep }\end{array}$ & Normal & .34026 & Weibull(3P) & -4.4725 & Normal & 15.704 \\
\hline
\end{tabular}

$(\mathrm{mm})$ were taken from daily rainfall. The various probability distribution functions are described in Table 1 . The annual maximum daily rainfall ranged from 41 to $307.9 \mathrm{~mm}$ during the study period and is presented in Fig.1. The data was classified into 23 data sets. These 23 data sets were classified as 1 annual (Jan to Dec.), 1 seasonal (June to Sept), 4 months of rainy season and 17 weeks ( from Standard Meteorological (week no.23 to 39) to study the distribution pattern at different levels. The summary statistics (mean, standard deviation, skewness coefficient, coefficient of variation, maxi-

mum and minimum values of daily maximum rainfall) are presented in Table 2. It is observed that mean of maximum daily rainfall of all years annually is 112.13 $\mathrm{mm}$, seasonal mean value is $111.17 \mathrm{~mm}$. The means of monthly and weekly values ranged from 33.10$88.92 \mathrm{~mm}$ and $8.77-46.28 \mathrm{~mm}$, respectively. The maximum daily rainfall in a year/monsoon season was $307.9 \mathrm{~mm}$. During different months (i.e. June, July, August \& September) of monsoon period , the maximum daily rainfall ranged from $105-307.9 \mathrm{~mm}$. The weekly maximum daily rainfall ranged from $48 \mathrm{~mm}$ - 
Table 4. Parameters of the best fitted distribution.

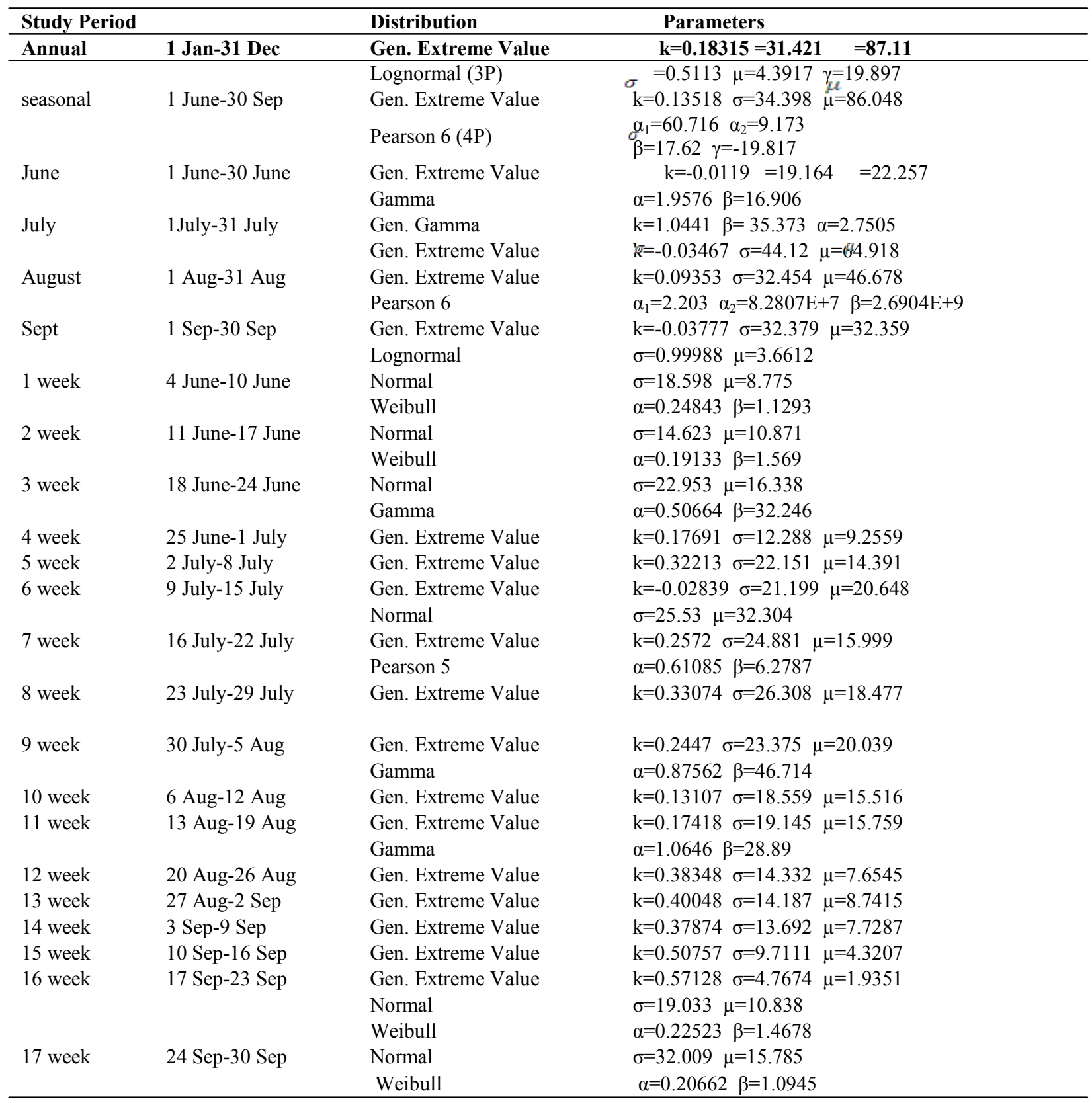

$307.9 \mathrm{~mm}$.

It was also observed that the minimum among the maximum daily rainfall was $41 \mathrm{~mm}$ for annual, $34 \mathrm{~mm}$ for season and 0 in all the months and weeks. The maximum value of coefficient of variation was observed in the first week which indicates a large fluctuation in the rainfall data set and minimum value of coefficient of variation 0.464 was observed for the whole year which shows that fluctuation was minimum for the whole year.

The test statistics $D, A^{2}$ and $\chi^{2}$ for each data set were computed for sixteen probability distribution and the probability distribution having the first rank along with their test statistic is presented in Table 3. It was ob- served that Generalized extreme value distribution using Kolmogorov Smirnov test, Generalized Extreme value using Anderson Darling test and Pearson(6) using Chi-square test obtained the first rank for maximum daily monsoon rainfall. Thus the two probability distributions were identified as the best fit based on these three tests independently. The months of July and August on which the monsoon period remained centered are best expressed by generalized extreme value followed by Pearson 6. The other two months i.e. June and September are best explained by Generalized extreme value, Gamma and Lognormal (2P).

The sum of total test score were obtained for each data set for all 16 probability distribution. This was done to 
Table 5. Score wise best fit probability distribution.

\begin{tabular}{lll}
\hline Study Period & \multicolumn{2}{l}{ Distribution with highest Score } \\
\hline \multirow{3}{*}{ Annual } & Distribution & Score \\
& Gen.Extreme Value & 41 \\
Seasonal & Pearson 5 & 43 \\
June & Gen.Exteme Value & 45 \\
& Gen. Extreme Value & 46 \\
July & Gamma & 45 \\
August & Gen. Extreme Value & 43 \\
Sept & Gen. Extreme Value & 46 \\
1 week & Gen. Extreme Value & 40 \\
2 week & Normal & 45 \\
3 week & Normal & 45 \\
4 week & Normal & 46 \\
5 week & Gen. Extreme Value & 48 \\
6 week & Gen. Extreme Value & 48 \\
& Gen. Extreme Value & 46 \\
7 week & Normal & 46 \\
8 week & Gen. Extreme Value & 44 \\
9 week & Gen. Extreme Value & 48 \\
10 week & Gen. Extreme Value & 47 \\
11 week & Gen. Extreme Value & 48 \\
12 week & Gen. Extreme Value & 47 \\
13 week & Gen. Extreme Value & 48 \\
14 week & Gen. Extreme Value & 48 \\
15 week & Gen. Extreme Value & 48 \\
16 week & Gen. Extreme Value & 48 \\
17 week & Gen. Extreme Value & 45 \\
\hline & Normal & 45 \\
\hline
\end{tabular}

identify the one more probability distribution in addition to distribution identified earlier for obtaining the best fit probability distribution. This distribution was identified using maximum overall score based on sum of individual point score obtained from three selected goodness of fit tests. The distributions identified which were having highest score are presented in Table 4.

The distributions with same highest score were also included in the selected probability distribution. For annual data set Pearson 5 (3P) having highest score of43 was selected. It was also observed that some of the probability distributions already having the first rank in Table 3 were also having the highest scores and hence three or less distributions were identified. The distributions so identified are listed in Table 5 where the parameters of these identified distributions for each data set are mentioned in Table 4. Weibull (3P) distribution was found to be the best fit among the 11 fitted distributions by the Krishnamurhy et al. (2015). As reported by the Bhim et al. (2012) log-Pearson distribution was found to be the best fit probability distribution. In our study the General extreme value distribution was found to be the best fit probability distribution. The results show that both annual and seasonal maximum daily rainfall was observed to be 307.9 in the current study whereas in case of Krishnamurthy et al. (2015) and Bhim et al. (2015), it was found to be $200 \mathrm{~mm}$ and $252.98 \mathrm{~mm}$ respectively.

\section{Conclusion}

Probability distribution of rainfall analysis has always attracted much attention due to erratic behavior over space and time. Thus the identifying the best distribution is of vital importance for better planning and management of the water especially for agrarian state like Haryana where agriculture pattern is intensive. Since India is facing the problem of drought in the year $2002,2004,2009,2014$ and 2015. So by studying the distribution of rainfall in the district or village level the water management can be done. In overall General extreme value distribution was found to be the best for annual, seasonal, weekly and monthly followed by

\section{Annual maximum daily rainfall}

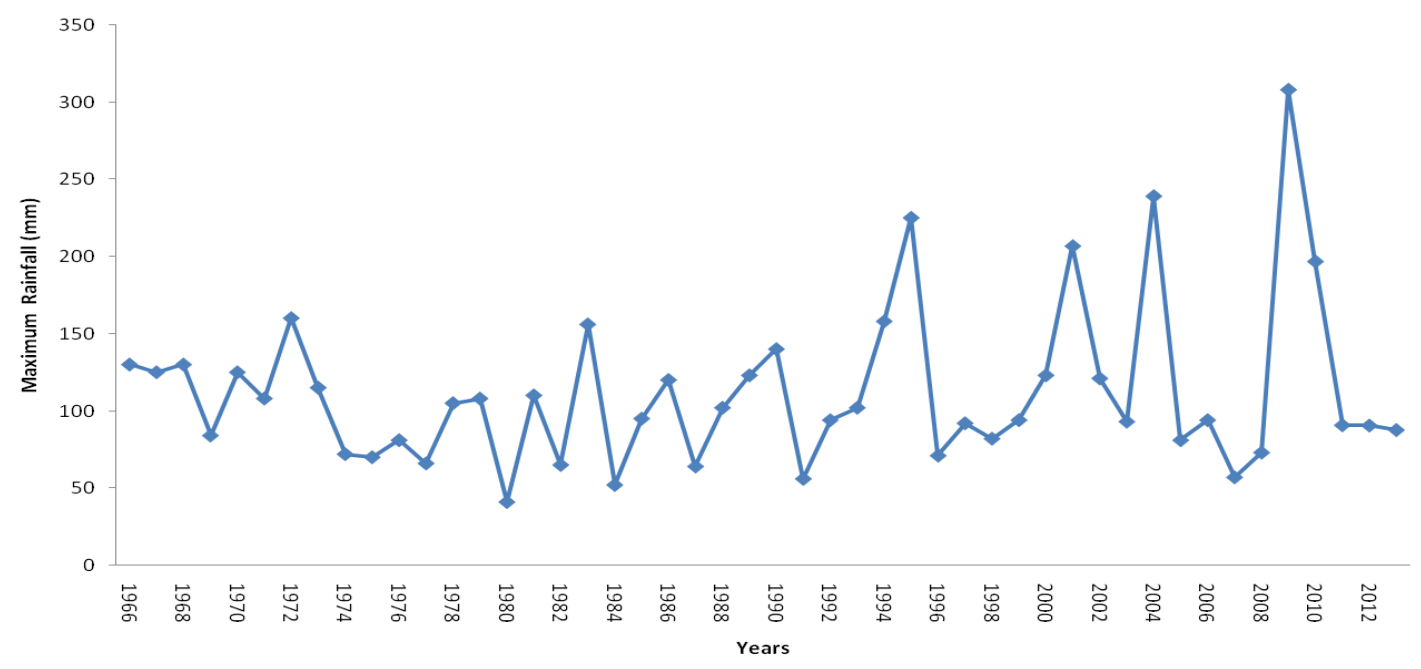

Fig. 1. Annual maximum rainfall (mm) at Ambala during 1966-2013 (Source: Indian Meteorological Department) . 
Lognormal (3P), Gamma and normal distribution.

\section{ACKNOWLEDGEMENTS}

The authors duly acknowledge and thankful to reviewer's for revision the manuscript and very informative suggestions.

\section{REFERENCES}

Bhakar, S.R., Bansal, A.N., Chhajed, N. and Purohit, R.C. (2006). Frequency analysis of consecutive day's maximum rainfall at Banswara, Rajasthan, India. ARPN Journal of Engineering and Applied Sciences, 1(3): 64-67

Bhim Singh, Deepak Rajpurohit, Amol Vasishth and Jitendra Singh. (2012). Probability analysis for estimation of annual one day maximum rainfall of Jhalarapatan area $f$ Rajasthan, India. Plant Archives, 12(2): 1093-1100

Duan, J., Sikka, A.K. and Grant, G.E. (1995). A comparison of stochastic models for generating daily precipitation at the H.J. Andrews Experiment Forest. Northwest

Hanson, L.S., and Vogel, R. (2008). The probability distribution of daily rainfall in the United States. Proc. In World Environment and Water Resources Congress Conference

Krishnamurthy, K.N., Gowda, D.M. and Vasanthkumar, T. (2015). Use of some probability distributions in rainfall analysis. Indian Streams Research Journal, 5 (6): 1-8

Kwaku, X.S., and Duke, O. (2007). Characterization and frequency analysis of one day annual maximum and two to five consecutive days maximum rainfall of Accra, Ghana. ARPN Journal of Engineering and Applied Sciences, 5: 27-31

Lee, C. (2005). Application of rainfall frequency analysis on studying rainfall distribution characteristics of Chia Nan plain area in Southern Taiwan. Journal of Crop, Environment \& Bioinformatics, 2: 31-38

Mayooran, T. and Laheetharan, A. (2014). The statistical distribution of annual maximum rainfall in colombo District, Sri Lankan. Journal of Applied Statistics, 15 (2): $107-130$

Ogunlela, A.O. (2001). Stochastic analysis of rainfall events in Ilorin, Nigeria. Journal of Agricultural Research and Development, 1: 39-50

Olofintoye, O.O., Sule, B.F. and Salami, A.W. (2009). Bestfit Probability distribution model for peak daily rainfall of selected Cities in Nigeria. New York Science Journal, $2(3)$

RamaRao, B.V., Kavi, P.S. and Sridharan, P.C. (1975). Study of rainy days and wet spells at Bijapur. Annual Annals Arid Zone, 14 (4): 371-372

Salami, A.W. (2004). Prediction of the annual flow regime along Asa River using probability distribution models. AMSE periodical, Lyon, France. Modeling C. 65 (2): 41 56

Sen, Z. and Eljadid, A.G. (1999). Rainfall distribution functions for Libya and Rainfall Prediction. Hydrol. Sci. J., 4 (5): 665-680

Takara, K. and Kobayashi, K. (2013). Frequency analysis of extreme events for disaster management. Journal of Disaster Research, 8 (1): 147-148

Tao, D.Q., Nguyen, V.T.. and Bourque, A. (2002). On selection of probability distributions for representing extreme precipitations in Southern Quebec. Annual Conference of the Canadian Society for Civil Engineering. 2002;5th - 8th June: $1-8$

Upadhaya, A. and Singh, S.R. (1998). Estimation of consecutive day's maximum rainfall by various methods and their comparison. Indian Journal of S.Cons., 26 (2): 193 $-2001$ 